\title{
Emerging proteomic approaches to identify the underlying pathophysiology of neurodevelopmental and neurodegenerative disorders
}

\author{
Nadeem Murtaza, Jarryll Uy and Karun K. Singh*
}

\begin{abstract}
Proteomics is the large-scale study of the total protein content and their overall function within a cell through multiple facets of research. Advancements in proteomic methods have moved past the simple quantification of proteins to the identification of post-translational modifications (PTMs) and the ability to probe interactions between these proteins, spatially and temporally. Increased sensitivity and resolution of mass spectrometers and sample preparation protocols have drastically reduced the large amount of cells required and the experimental variability that had previously hindered its use in studying human neurological disorders. Proteomics offers a new perspective to study the altered molecular pathways and networks that are associated with autism spectrum disorders (ASD). The differences between the transcriptome and proteome, combined with the various types of post-translation modifications that regulate protein function and localization, highlight a novel level of research that has not been appropriately investigated. In this review, we will discuss strategies using proteomics to study ASD and other neurological disorders, with a focus on how these approaches can be combined with induced pluripotent stem cell (iPSC) studies. Proteomic analysis of iPSC-derived neurons have already been used to measure changes in the proteome caused by patient mutations, analyze changes in PTMs that resulted in altered biological pathways, and identify potential biomarkers. Further advancements in both proteomic techniques and human iPSC differentiation protocols will continue to push the field towards better understanding ASD disease pathophysiology. Proteomics using iPSC-derived neurons from individuals with ASD offers a window for observing the altered proteome, which is necessary in the future development of therapeutics against specific targets.
\end{abstract}

\section{Autism spectrum disorders}

Autism spectrum disorders (ASD) are a broad range of neurodevelopmental disorders, ranging in severity between individuals. It is defined by two core symptoms, impaired social communication and reciprocal interaction, and the presence of repetitive behaviors and restricted interests. Due to heterogeneity in ASD,

\footnotetext{
* Correspondence: singhk2@mcmaster.ca

Stem Cell and Cancer Research Institute, Department of Biochemistry and Biomedical Sciences, McMaster University, 1280 Main Street West, Hamilton, ON L8N 3Z5, Canada
}

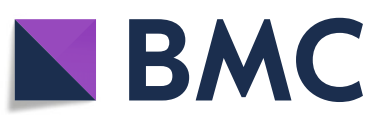

treatments are currently focus on the associated symptoms of ASD, specifically irritability and aggression through either risperidone or aripiprazole, both originally prescribed as antipsychotics [1]. However, elucidation of biological pathways underlying ASD is required before new therapies can be developed. In this review, we explore emerging technical advances in proteomics that provide new tools to gain insight into novel and clinically relevant ASD signaling networks, which can be applied to models, such as patient-specific induced pluripotent stem cells (iPSCs). 


\section{Current research approaches in ASD}

Large-scale genome sequencing studies have identified numerous ASD risk genes (reviewed by Iakoucheva et al. [2]), which have for the most part, been studied using animal and human models [3] (Fig. 1). Many major cellular pathways have been associated with ASD pathophysiology, including growth and activity, synaptic transmission, excitatory/inhibitory balance, plasticity, protein synthesis, and neuron-glia signaling (reviewed by Chen et al. [3]), and metabolic signaling and mitochondrial function (reviewed in [4]; however, studying individual genes/pathways is a time-consuming and a costly process. In addition, human imaging or post-mortem studies have pinpointed neuroanatomical and brain connectivity differences. For example, structural magnetic resonance imaging (MRI) and diffusion tensor imaging (DTI) revealed decreased connectivity in the corpus callosum, structural shifts and increased activity in the frontal lobe, and altered connectivity across cortical regions and within the limbic system involved in memory and emotions (reviewed in $[3,5])$. A recent study showed an increase in the metabolic rates of neurons crossing the corpus callosum in individuals with ASD and SCZ [6]. Post-mortem imaging studies have identified phenotypes including, atypical cortical column development, altered neuronal density in cortical layers II/III and V, and increased inflammation and glial activity (reviewed in $[3,5]$ ). These studies reveal aberrant connectivity between regions of the brain, especially in the cortex and cerebellum, which are highly associated with ASD.

Studies of the transcriptome have been key for identifying disrupted networks [7, 8] (reviewed by QuesnelVallieres et al. [9]), but a caveat of these studies is the discordance between mRNA levels and protein levels [10]. Although steady-state mRNA does correlate with protein, and both can be used to distinguish cell and tissue types $[11,12]$, it does not directly match protein expression levels $[13,14]$. Perturbations to the cell can drastically shift the correlation between mRNA and protein due to delayed mRNA translation, differential sub-cellular localization of mRNA, and post-translational modifications (Fig. 2). Very few studies in the ASD field have analyzed the proteome and therefore the actual changes in protein levels are not fully understood. Furthermore, post-translation modifications (PTMs) can greatly affect protein activation, binding affinity, and folding and turnover rates [15, 16] (Fig. 2). Transcriptome research remains an important part of ASD

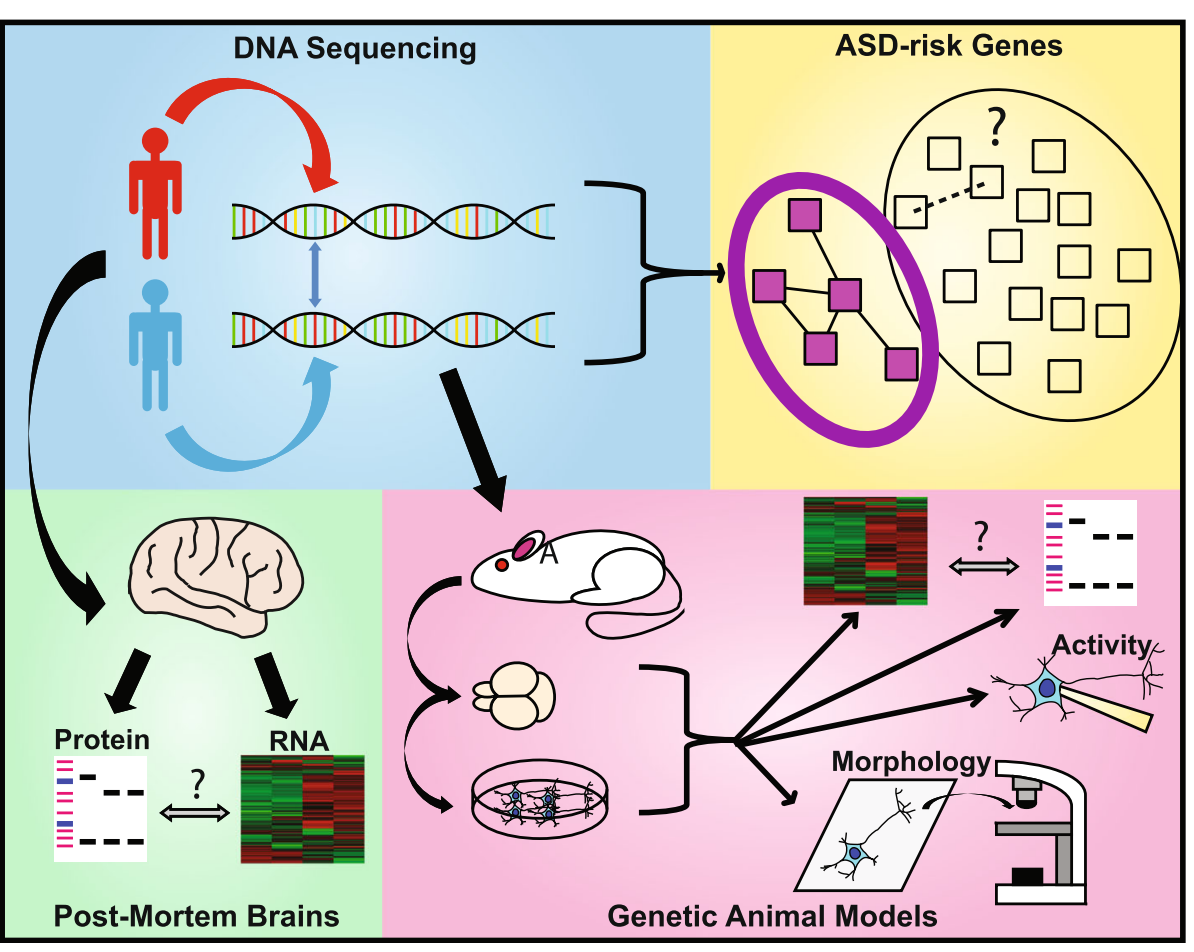

Fig. 1 Current research in ASD. Current ASD research focuses on genetic sequencing studies to identify ASD risk genes, based on the enrichment of single nucleotide or copy number variations. Following identification, post-mortem brains from individuals with ASD are used for analysis of the proteome or transcriptome, and single genes are studied using animal models. Animal models are studied in vivo and in vitro for changes in neuron morphology and activity as well as in the transcriptome and proteome. Post-mortem brains are limited in availability and do not provide insight into the early developmental time points directly, while animal models only study one gene at a time, resulting in the low throughput elucidation of disease-relevant mechanisms for only a minority of ASD-risk genes 


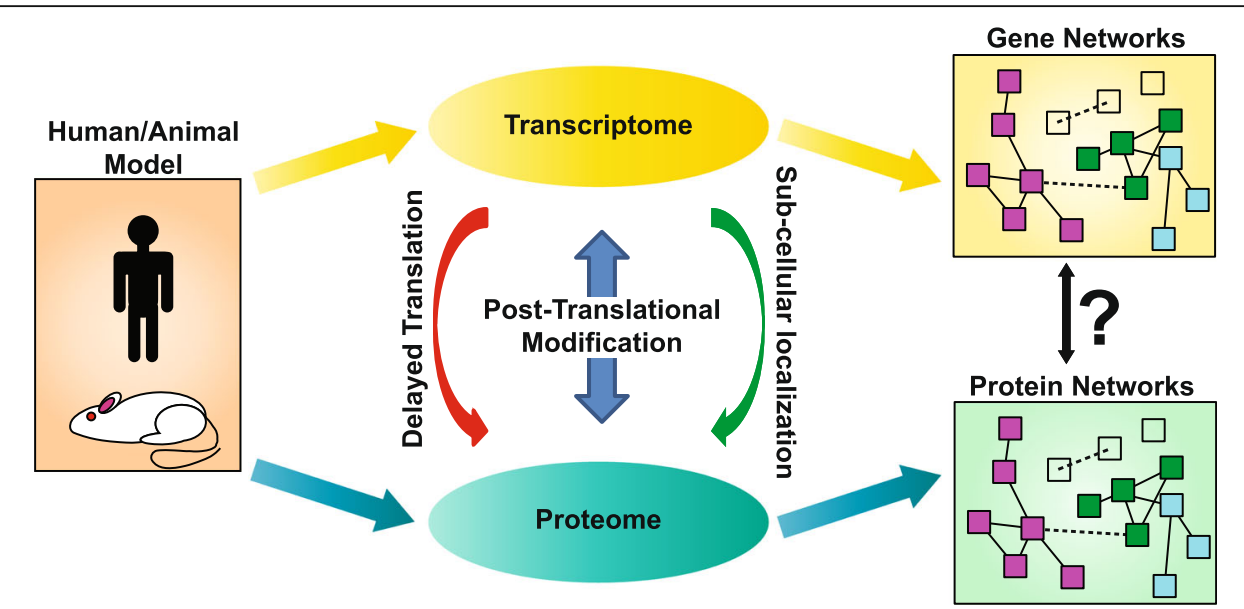

Fig. 2 Identification of molecular networks using the transcriptome and proteome. Investigation into the transcriptome and proteome in both human and animal models have resulted in biological networks based on RNA and protein. Differences between the transcriptome and proteome due to delayed translation, post-translational modificaton, and sub-cellular localization could lead to discordance between these two sets of networks

investigations; however, the proteome is still greatly unmapped and has the potential to drastically advance our understanding of neurological disorders.

\section{Altered biological processes in autism spectrum disorders}

ASD-associated genes can also be categorized into many major gene networks including cytoskeleton, channels, post-synaptic density, chromatin, and intra-cellular signaling $[17,18]$. A recent study shows that ASD-associated genes can be grouped into two broad and distinct categories, gene regulation and neuronal communication [19]. Multiple biological processes have been associated with ASD through studying genetic animal models [3]. Most studies use large annotated databases, such as Gene Ontology, KEGG, or REACTOME, to identify the biological processes enriched by ASD risk genes. These networks are generally based on meta-databases that rely on known pathways and interactions. However, they rely majorly on RNA co-expression datasets that do not reflect the changes at the protein level, or on interactions identified in non-neuronal or non-mammalian models. This is further the case with RNA sequencing and single-cell RNA sequencing, where many pathways are identified through the transcriptome. Mass spectrometry is a versatile technique that allows the study of the entire proteome and to date has only been used minimally to study ASD. Thus, we will focus on different approaches that use mass spectrometry to study changes in the proteome.

\section{Proteomic approaches to study signaling networks}

Mass spectrometry (MS) is the popular choice to study proteomics due to its ability to handle complex protein samples with high resolution. It is highly versatile and can be applied to study protein abundance, PTMs, and protein interactions. Proteins from biological samples are ionized into fragments and then into precursor ions for detection by a specific mass analyzer. The two most common ionization tools are liquid chromatographyelectron spray ionization (LC-ESI) and matrix-assisted laser desorption ionization (MALDI) [20]. LC-MS is typically the preferred method for analyzing complex protein/peptide mixtures; on the other hand, MALDI-MS is used to analyze simple peptide mixtures $(<100$ proteins), such as blood, urine, and saliva [21].

\section{Quantitative proteomics}

There are two methods of quantitative proteomics, topdown and bottom-up (Fig. 3a, d). Top-down proteomics is generally used to analyze simpler protein mixtures and allows for high coverage and characterization of a protein's "proteoform," the variable form of a protein due to genetic variation, alternate splicing, and PTMs [22]. Top-down proteomics is an excellent choice when investigating specific proteins of biological importance to observe changes in the proteoform, possibly by PTMs. However, it lacks proteome-wide coverage, sensitivity, and high-throughput capacity limiting its usage to pure or simple protein samples. The majority of workflows are bottom-up, also called shotgun proteomics [23]. Tandem-MS (MS/MS) is typically used in bottom-up proteomics, and LC-MS/MS is the most common method for quantifying proteins on a global scale. The high sensitivity allows for the detection and quantification of low abundant molecules, specific PTMs, and protein-protein interactions, and the characterization of subcellular compartments [24]. In contrast to top- 


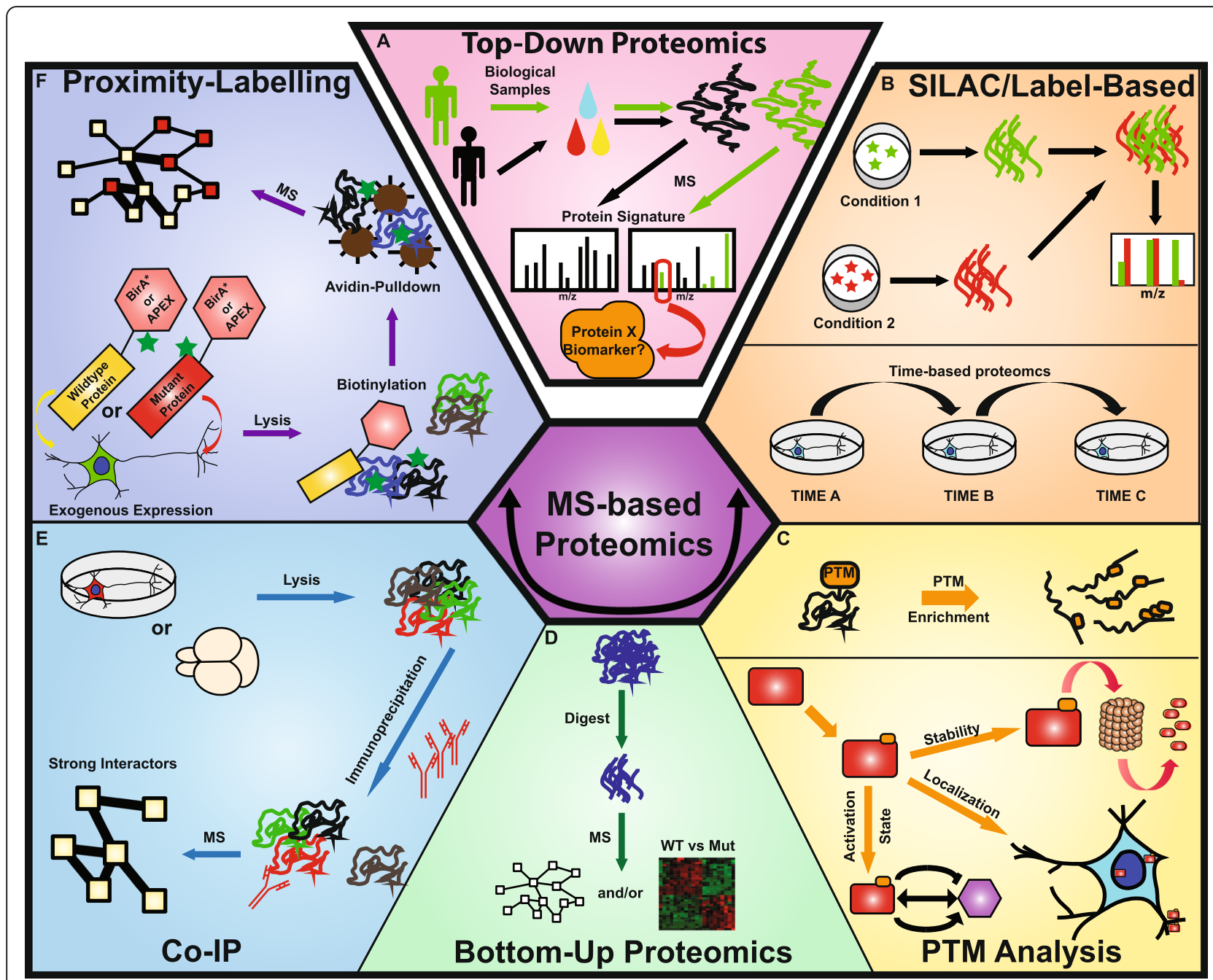

Fig. 3 Studies in neurodevelopmental disorders using MS-based proteomics. (a) Top-down proteomics allows the identification of protein signatures and specific proteins altered in biological samples, such as blood, urine, and saliva, from affected and unaffected individuals. (b) SILAC and label-based proteomics can be used to combine multiple samples to reduce variability and allow normalization across samples, presenting a powerful tool for time-course based studies in vitro and in vivo. (c) PTM analysis allows the identification of protein modifications that regulate the activity, localization, and stability of the protein. (d) Bottom-up proteomics relies on the digestion of proteins into peptides to allow more precise and accurate quantification and identification through mass spectrometry. It allows for the use of SILAC and label-based proteomics, identification of PTMs, and the ability to identify PINs using proximity-labeling or Co-IP. (e) Co-IP uses antibodies or affinity tags to isolate endogenous proteins and identify strongly interacting proteins that are simultaneously pulled-down, through mass spectrometry. (f) Proximity labeling uses the expression of a protein of interest fused to a labeling-protein, such as BirA* or APEX, which biotinylates proteins in close proximity. These proteins, which include strong and transient interactors, can then be isolated using an avidin pull-down and identified through mass spectrometry. Proximity labeling can allow for the comparison between wildtype, mutant, or condition-treated PINs

down methods, bottom-up strategies can have higher coverage and increased high throughput and multiplexing of samples.

\section{Label-free protein quantification}

Label-free quantification (LFQ) is a MS-based proteomic method that determines the relative or absolute amount of proteins between biological samples. LFQ methods are able to achieve higher sequence coverage than labelbased methods, allowing for highly reliable protein identification [25]. Due to the ability to run multiple samples without limit, it is excellent for identifying changes in multiple cell and tissue types. One study tracked changes in the proteome of old and young mice with Alzheimer's disease (AD) pathology and found that there was an increase of amyloid beta proteins coupled with a decrease in AMPA receptor trafficking proteins over time [26]. It has also been used for bottom-up proteomics, including the region-specific analysis of the Shank3 mouse model of syndromic ASD [27]. However, LFQ is more prone to instrumentation error and variability between runs, which can be reduced through standard or sample-spiking strategies [28]. 


\section{Label-based protein quantification}

Label-based proteomics is achieved using chemical or metabolic tags. The most popular choice are the isobaric tags for relative and absolute quantification (iTRAQ) $[29,30]$. These tags can be used to multiplex up to eight samples. Similar to iTRAQ is the tandem mass tag (TMT), which can multiplex up to 16 different samples [31]. Chemical labeling allows for samples to be mixed together as "one" sample and run at the same time, which allows for comparison between samples and reduces variability (Fig. 3b). However, there are some practical drawbacks including the labeling efficiency, which may fluctuate between samples. Technical differences introduced by isobaric labeling can also be avoided by using the alternative metabolic labeling.

\section{Metabolic labeling of proteins through stable isotope labeling with amino acids (SILAC)}

The most conventional metabolic labeling technique is stable isotope labeling with amino acids in cell culture (SILAC), which involves feeding cells media containing isotopic amino acids [32] and can be mixed for subsequent processing for mass spectrometry (Fig. 3b). This allows for detection of differences in protein abundances in cell cultures and can be modified to examine de novo protein synthesis $[33,34]$. SILAC has been used to study neurodevelopmental and neurodegenerative disorders $[35,36]$. SILAC on primary cultures of Fmr1 KO mice cortical neurons showed decreases in synaptic proteins and mRNA transport [37]. Tang et al. used the same technique and showed that loss of Fmr1 may have a larger impact during early postnatal brain development, showing an increase of pre- and post-synaptic proteins [38]. Furthermore, SILAC has been used to study ASDassociated de novo mutations in the E3 ubiquitin ligase, UBE3A. Profiling of wild-type UBE3A or the T485A mutant using SILAC-MS combined with ubiquitin affinity profiling determined that mutant UBE3A interacts with and ubiquitinates multiple subunits of the proteasome complex, decreasing its stability and causing overactive Wnt signaling [35]. While SILAC has not been employed widely in other ASD-associated models, using it on genetic knock-out or knock-in models can identify changes in the neuronal proteome over time (Fig. 3b). While most studies are still done in vitro, progress has been made for in vivo SILAC labeling [39-43].

\section{Identifying and quantifying post-translation modifications}

PTMs are important as they can alter a protein's spatialtemporal function by changing its conformation, activity, or stability (Fig. 3c). Proteomics, unlike genomics, allows the opportunity to directly identify PTMs in a selective manner through specific purification methods [44].
Alterations in PTMs have been implicated in multiple neurodegenerative disorders $[45,46]$. There are many types of PTMs, including phosphorylation, methylation, palmitoylation, glycosylation, acetylation, SUMOylation, ubiquitination, and S-nitrosylation. Phospho-proteomics can map differential phosphorylation of kinases and phosphatases and their substrates, and it has been used to identify novel altered pathways in $\mathrm{AD}, \mathrm{ASD}$, and other neurological disorders [47]. For example, investigation of the phospho-proteome in AD cell line models and post-mortem brain samples has revealed the involvement of specific kinases in heat shock proteindependent protein folding, insulin-mediated signaling, p53 regulation, and neuronal autophagy [48-50]. Studying the relevant ASD phospho-proteome, SILAC-MS of mouse Fmr1 KO mouse embryonic fibroblasts revealed multiple changes to the MAPK, mTOR, Wnt, and p53 signaling pathways [51]. Although these pathways were previously linked to altered translation and neurogenesis in ASD, they showed that differential expression and phosphorylation of multiple proteins are involved in each pathway. In addition to global changes, phosphoproteomics can detect changes in specific cellular compartments. Collins et al. published one of the first mouse synapse phospho-proteomes and identified 331 phosphorylation sites in the pre- and post-synapse [52]. More recent work identified 1554 phosphorylation sites in the post-synaptic density, which are altered during neuronal stimulation [53]. These studies highlight the complex regulation of synaptic proteins that is missed using transcriptomics. In addition to phosphorylation, an investigation using Shank3 mutant mice found large changes in the S-nitroso-proteome, which altered vesicle release at the presynaptic terminal [54]. Interestingly, changes in the S-nitroso-proteome has also been associated with a tauopathy model of AD [55]. Methylation of histone complexes is another topic of interest, as many ASD genes are linked to chromatin remodeling. For example, SETD5 happloinsufficiency revealed that SETD5 methylates histones directly, suggesting an important role of H3K63 methylation, which in turn regulates RNA elongation and processing [56]. Together, these studies emphasize how important PTMs are for protein regulation and function.

\section{Identifying protein-protein interaction networks (PINs)}

Proteomics studies can provide direct information about the altered protein levels in genetic mouse models of ASD; however, they cannot identify the networks that are directly regulated by the protein. The increasing number of genes identified in neurodevelopmental disorders highlight the obstacles in identifying relevant pathways $[35,36]$. Traditionally, protein-protein interactions 
(PPIs) were identified using two-hybrid screens; however, there are now multiple proteomic-based methods, such as affinity pull-down or co-immunoprecipitation and proximity labeling, which are discussed here.

Two-hybrid $(2 \mathrm{H})$ screening is used as a confirmation tool to determine if two proteins are in close proximity or interacting directly [57]. This method uses both bait and prey proteins that are fused to separate fragments, which when in close enough proximity come together to produce an output. In 2011, Sakai et al. used yeast twohybrid (Y2H) with a human cDNA library of 192 bait fragments and identified 848 interactions with 26 syndromic ASD or ASD-associated proteins, where only 32 interactions were previously known [58]. Their screen identified proteins localized to the synapse, post-synaptic density and the cytoskeleton, that involved small GTPase-mediated signaling and metabotropic glutamate receptor signaling, demonstrating the utility of $\mathrm{Y} 2 \mathrm{H}$. Corominas et al. later used $\mathrm{Y} 2 \mathrm{H}$ on 422 splicing isoforms from 168 autism candidate genes and identified 506 protein-protein interactions between 71 bait and 291 prey proteins [59]. They found that one third of the gene-level interactions would not be identified if only using the reference isoform, suggesting a strong role for altered splicing in ASD. Although $2 \mathrm{H}$ screens provide direct evidence of interactions, they are only identified between fragments used in the screen, therefore biasing results. $2 \mathrm{H}$ methods also generally require the use of less complex organisms and it is not adapted for human cell models; however, new proteomics technologies may be better suited for detecting novel PPIs in human cells.

\section{Affinity pull-down and co-immunoprecipitation}

Affinity pull-down or co-immunoprecipitation (Co-IP) coupled with mass spectrometry is an approach to identify interacting proteins (Fig. 3e). After cell lysis and pull-down using an antibody, mass spectrometry can be used for protein identification. In some cases, the protein of interest can be fused to an affinity tag [60]. IPmass spectrometry has been used to identify the interacting proteins for important neuronal channels including AMPA and kainate receptors [61]. The Grant group used this method to identify the interactome of the NMDA and AMPA receptors and the PSD95 scaffold protein [62-64]. Additional investigation of the PSD using biopsies and post-mortem brain samples revealed that $14 \%$ of proteins in this compartment are associated with nervous system disorders and were highly conserved between species [65]. Bayes et al. further described an increased association between MAGUKassociated proteins and ASD within the synaptic compartment [66], while a study of the mouse PSD proteome during two developmental time points revealed differential association between PSD95 and SHANK3
[67]. These studies were the first to describe a strong connection between an altered synaptic proteome and ASD. Using Co-IP, Berg et al. identified the PIN of JAKMIP1 in mouse cortical neurons, a gene that is differentially expressed in patients with Fragile X syndrome and $\operatorname{dup}(15 q 11-13)$ syndrome [68], demonstrating that it is involved in translation, including FMRP and FMRP targets. Co-IP also identified new functions of proteins within specific cellular compartments. Cytosolic DYRK1A was originally associated with cell cycle and cytoskeleton organization $[69,70]$, but a novel function for DNA damage repair was shown in the nuclear compartment [71]. In addition, the functional impact of genetic mutations was described showing ADHD-linked mutations in the $\mathrm{Na}+\mathrm{H}+$ exchanger 9 protein (encoded by SLC9A9) alters the interaction with caveolae-mediated endocytosis and MAP2K2mediated signaling [72]. Finally, 11 ASD-associated genes were investigated using IP-mass spectrometry and shared signaling mechanisms between FMRP and MECP2, and idiopathic and non-idiopathic ASDs were discovered [73]. Together, these studies highlight the value of using Co-IP mass spectrometry as an important tool in identifying PINs.

Technical limitations of Co-IP include the strength of the interaction after cell lysis, quality of the antibody, and the use of appropriate controls. However, techniques such as chemical cross-linking mass spectrometry have been used to identify more transient interactors in the synaptic compartment [74]. Co-IP works well with scaffold and adherent proteins that are enriched in the synaptic compartment (e.g., SHANK or HOMER). Although cross-linking is a potential method of trapping transient interactions, it can also introduce artifacts. A Co-IP study of 16 proteins in seven ASD mouse models was able to cluster the models based on synaptic interaction strength and successfully predicted deficits in the AKT pathway in the Ube3a mouse model [75]. Although this study was not coupled to mass spectrometry, it suggests the potential of the method for concurrently studying different models of ASD using Co-IP/MS.

\section{Proximity-based labeling of proteins}

Proximity-based protein labeling coupled to MS has been a ground-breaking method for identifying proteinprotein interactions (PPIs) [76]. It allows the screening of endogenous PPI networks in live cells (Fig. 3f). Labeling proteins in cells prior to harvesting reduces artifacts due to presence of detergents and isolation steps. Proximity labeling has the advantage of identifying weak and transient interactions, which are common in metabolic and intracellular signaling. The method requires the proximity labeling of neighboring proteins, rather than direct physical protein interactions, which can be identified long after the interaction has ended. 
There are two major methods, engineered ascorbate peroxidase (APEX) or the promiscuous BirA* biotin ligase (BioID) $[77,78]$. BirA* uses ATP to create active biotin that labels lysine residues, while APEX utilizes biotin-phenol that is activated by hydrogen peroxide and labels tyrosine [79]. Biotinylation allows the labeling of nearby proteins that can be pulled down using affinity chromatography against biotin and run through the mass spectrometer. APEX and BioID have mainly been used to identify the proteins in cellular compartments or signaling pathways in mammalian cells lines such as HEK293 cells [80-86]. Only two studies have used APEX on cultured cortical neurons, focusing on the identification of proteins in the synaptic cleft or the identification of the RNA localized to different cellular compartments $[87,88]$. These studies required a large number of neurons ( $>90$ million cells), possibly due to quick activation dynamics. The development of proximity-labeling methods to reduce the number of primary cells required would increase throughput of testing different NDD risk genes to build comprehensive PPI networks. A recent BioID study used hippocampal cultures and mapped the axon initiation segment (AIS) by BirA* tagging multiple AIS proteins, including NF186, Ndel1, and Trim46. They identified previously unknown proteins necessary for proper AIS formation, such as Mical3, although some known AIS associated proteins were not identified [89]. In the first use of BioID in vivo, PSD95 (excitatory synapses) or gephyrin (inhibitory synapses) was fused to BirA* and expressed in the mouse brain, identifying known and novel interactors [90] and revealing new inhibitory signaling. Another study from the same group later characterized the interactome of CARMIL3 and showed it interacted with cytoskeleton proteins in the synapse as a new synapse regulator [91]. However, in vivo BioID requires the use of adeno-associated virus that has smaller packaging size limitations, preventing the study of larger proteins, many of which are encoded by ASD risk genes and expressed in the brain.

Although proximity labeling is a powerful approach, users should be aware of limitations. APEX requires the addition of hydrogen peroxide and cannot be used in vivo due to toxicity. Tyrosine residues are among the least abundant amino acids in and therefore could result in missed labeling [92]. Alternatively, BioID only requires ATP and biotin, which are found in all cells and labels one of the most common amino acids, lysine. BioID offers more versatility using in vitro or in vivo models and has a higher chance of labeling all proteins within its active radius. However, the incubation and label time required is $15-24 \mathrm{~h}$, while APEX requires only 30-60 min and can label proteins within a minute [93]. For these reasons, BioID is generally used to identify a history of interacting proteins, while APEX can capture interacting proteins during a short period of time. A newer version of BioID, called TurboID, allows biotin labeling within a 10-min time frame, creating the opportunity to study dynamic changes in PINs [94].

BioID has not yet been reported to be used in iPSCderived neurons or brain organoids where it will be very useful to identify distinct and shared human signaling networks. It is important to remember that endogenously biotinylated proteins are always present and could create a background of biotinylated proteins. The proper controls are therefore required to compare the experimental condition to a control [87]. However, overexpression of the protein of interest can alter the state of the cell, and therefore, a proper control should express the protein of interest, as well. The use of self-cleavage $2 \mathrm{~A}$ sequences may be beneficial because it allows the expression of the protein and proximity-labeling enzyme simultaneously and separately, so that both conditions only differ in the protein fusion [95].

\section{Proteomic analysis of post-mortem brains from individuals with ASD}

Studying neurological disease in the human brain is difficult due to the inability to acquire live samples. Postmortem brains offer a way to study the human brain directly and have been used in a limited fashion to study ASD [96-98] (Fig. 1). RNA sequencing analysis of postmortem ASD brain samples revealed multiple significant changes in long non-coding RNAs, gene splicing events and gene expression [7, 99]. However, the correlation between the gene expression and protein expression is not fully understood. In one of the first uses of proteomics on post-mortem ASD brain samples, two brain regions, Brodmann area 19 (BA19) and the cerebellum, were investigated in idiopathic ASD. They identified distinct proteomes of each region and pathway analysis revealed changes in synaptic scaffold, glutamatergic transmission, calcium signaling, and neurofilament proteins; however, the proteomic signatures of both regions were not different between controls and ASD brains. This data refutes previous RNA sequencing data from postmortem studies and suggests there are brain regional molecular differences in autism. Moreover, the proteomic data in this study unexpectantly pointed to potential dysregulation of protein expression in ASD brains might be through upstream regulates that have common signailng pathways with neurodegeneration. Another study by Broek et al. used mass spectrometry to measure 14 chosen proteins in the prefrontal cortex (PFC) and the cerebellum of ASD and control individuals [96]. They also identified opposing regional differences in proteins related to myelination, synaptic function, and energy metabolism, but a similar decrease in the astrocyte marker protein, vimentin [100]. It is worth nothing that multple post-mortem proteomic 
studies have been undertaken for schizophrenia and bipolar disorders, revealing similar dysregulated pathways [101-103]. Limitations to using postmortem tissue include the limited availability of subjects or age-matched controls, exposure to alcohol or other neurological treatments that may alter the proteome, and post-mortem tissues have already begun the process of cell death that can confound results. In this regard, Bayes et al. describe differences in protein integrity between live biopsy and post-mortem samples between different regions in the brain and found that protein complexes in the synaptic compartments are more stable than other compartments [66]. To counteract these limitations, immotalized cell lines, such as subject lymphoblastoid cell lines, can be used. Researchers identified 82 proteins altered in ASD subgroups that have sever language impairment and reductions in the diazepam-binding inhibitor protein correlated with the autism diagnostic interview-revised scores [104]. However, these types of cell lines are difficult to interpret because they are non-neuronal.

\section{Proteomic studies to identify biomarkers using live patient biological specimens}

The limitations in obtaining the human brain historically has forced studies to use easily accessible samples, including urine, blood, and saliva. Analysis of urine identified changes in metabolites, toxins, and proteins as potential markers associated with ASD, but the relevance remains in question because the samples contain salts, which may skew mass spectrometry results. Blood offers a live biological samples for mass spectrometry, where MALDI-TOF was used to identify proteins that are changed in ASD (or subtypes of ASD) in several studies [105-107]. More specifically, differences in protein signature between subgroups of Rett syndrome have been identified [107]. Bottom-up proteomics have revealed consistent changes in proteins involved in mitochondrial function, ER stress and protein folding, endocytosis and immune response, and metabolites, including in children with mental regression [108, 109]. Wei et al. identified reduced levels of the STOP/MAP6 protein in the blood plasma of autistic children [110]. Similar analyses of urine and saliva have identified metabolites and compounds altered in individuals with ASD [111-114]. Proteomic analysis of SCZ and psychosis patient samples have also identified possible proteomic signatures, highlighting its use to identify disease biomarkers for both NDDs and other neurological disorders $[115,116]$. The major disadvantage to using these biological samples is the innate differences of cell types found within the blood, lymphatic, and urinary systems, which can potentially introduce proteins not relevant to the disease.

\section{Using human induced pluripotent stem cells (iPSCs) to study ASD}

Human iPSCs allow the study of human neurological disorders with a human genetic and biological background, which is not possible in animal models $[117,118]$. Human iPSCs are routinely now generated using skin fibroblasts or blood cells [119-122]. There are some considerations when using iPSCs, for proteomics studies. The differentiation of iPSCs into neurons may produce mixed cell types, which can confound proteomic findings [117, 123-125]. Furthermore, human iPSC-derived cells cannot fully address the altered brain connectivity observed in neurodevelopmental disorders, although co-culturing of multiple human-derived cell types or $3 \mathrm{D}$ organoids can provide more complex systems. In addition, large numbers of iPSCs are needed to generate sufficient neural cells for proteomic studies, which can be cost prohibitive. However, with recent advances in mass spectrometers, the amount of sample needed for signal has been steadily declining [126, 127].

\section{Proteomic analysis of 2D human iPSC-derived neuron cultures}

Targeted mass spectrometry of neurons differentiated from iPSCs identified increased expression of pre- and post-synaptic proteins (e.g., STXBP1, SYN1, VAMP2, GRIA1, and SYNGAP), suggesting that major neuronspecific proteins can be identified [128]. In an investigation of mutations in MECP2 associated with Rett syndrome, SILAC-MS was used to reveal that NPC-derived neurons with the Q83X or N126I mutations exhibit a downregulation of multiple astrocytic markers (ALDOC, S100B GFAP) in 3-week-old neural cultures [129]. Further investigation using SILAC revealed that NPCs lacking MECP2 have increased expression of LIN28, which is known to repress differentiation into glial cells [130]. A recent study using iPSC neuron of Rett syndrome patients identified 4 subsets of proteins that were differentially expressed, across time points involved in filipodia assembly, synapses, axon guidance, and cytoskeleton and translation [131]. This showed distinct temporal deficits during neuronal development, highlighting the fluid pathology underlying Rett syndrome.

Mass spectrometry to identify PTMs of proteins has also been applied to neurodegenerative models. PTMs in the tau protein were found using iPSCs generated from individuals diagnosed with frontomporal dementia and possessing the A152T mutation in MAPT (which encodes for the tau protein) [132]. They characterized differences in MAPT splicing and tau PTMs, showing that A152T neurons had increasing levels of tau. Another group identified altered phosphorylation and cysteine modifications in the cytoskeleton and RhoA signaling proteins in dopaminergic neurons with loss of PARK2 
[133]. Further, when comparing differentially expressed proteins in spinal muscular atrophy iPSC-derived motor neurons to their source fibroblasts, the iPSC-derived motor neurons had fewer proteins than controls, including proteins involved in viability (beta III-tubulin and UCHL1) and UBA1 involved in protein degradation signaling [134]. This study showed an important role for SMN (mutated in SMA) in the differentiation capacity of iPSCs to produce motor neurons.

The same methodology can be used to track the changes in the proteomic profile of other differentiation protocols. Varderidou et al. used two iPSC to neuron differentiation protocols, expression of NGN2 to generate excitatory neurons and small molecules to generate motor neurons [135]. Interestingly, they compared both the proteome and transcriptome during neuronal differentiation and found that both methods have different signatures, highlighting significant differences between the RNA and protein levels within human engineered neurons.

Mass spectrometry has also been used to study the proteome of non-neuronal brain cells. Differentiation of iPSCs from patients with Costello syndrome, a neurodevelopmental disorder, casued by heterozygous mutations in RAS (HRASG12S), revealed an increased differentiation and maturation into astrocytes. To identify the extracellular proteins produced by mutant astrocytes, shotgun mass spectrometry was used to identify an enrichment of extracellular matrix remodeling proteins and proteoglycans, which have an important role during critical periods of maturation and synaptic plasticity [136]. Finally, quantification of proteins in the cultured media of iPSC-derived neurons provides a potential avenue to identify disease biomarkers. For instance, reduced levels of ORM1 have been found in the culture media of iPSC-derived neurons from patients with AD, which coincides with reduced ORM1 levels that have been found in the cerebrospinal fluid of $\mathrm{AD}$ patients [137]. This finding highlights the utility of identifying disease biomarkers through mass spectrometry of iPSCderived neuron media [137].

\section{Proteomic analysis of 3D human iPSC-derived neuron cultures}

Advancements in neural differentiation of iPSCs has allowed for the generation of 3D human neuron cultures, known as organoids [138-140], which have better maturation profiles. Multiple different brain regionspecific organoids can be generated with a combination of sequentially introduced chemical modulators [141], allowing better recapitulation of brain development, making them a critical system for evaluating neurodevelopment [142]. Nascimento et al. used label-free shotgun proteomics to study human cerebral organoids and identified > 3000 proteins from neuronal progenitors, neurons and glial cells, and proteins relevant to neurodevelopment including axon guidance, synaptogenesis, and cerebral organoids [143]. Furthermore, disease-specific brain organoids were derived from patients with $A D$, subjected to LC-MS/MS, identifying altered proteins belonging to axon growth, mitochondrial function, and antioxidant defense [144]. Analysis of post-mortem brain tissues from $\mathrm{AD}$ patients showed similar findings indicating the power of the organoid culture system using proteomics. Another study examined how the 16p13.11 microduplication affected neurodevelopment using cerebral organoids [145]. Transcriptomic analysis of patientderived cerebral organoids showed perturbations in the NFkB p65 pathway, confirmed through proteomic analysis and highlights the growing interest to combine proteomics with patient iPSC-derived cerebral organoids in studying NDDs. We predict this system will be used further given the advanced maturation in patient-derived organoids, where proteomic-based methods can be used to identify the complex disease signaling networks.

\section{Statistical analysis of proteomic data}

Mass spectrometry requires the mapping of peptides and proteins, based on their spectral signature, to annotated protein databases (reviewed in [146, 147]). However, the matching of spectra between an experimental dataset and the protein/peptide database allows the possibility of incorrect identifications. Proteins identified have an associated minimal false discovery rate for incorrect identification, allowing for lenient or strict identification. Furthermore, due to the similarities between multiple proteins, especially isoforms and proteins of the same family, most studies use a minimal cutoff of 2 unique peptides for the identified proteins. There are many analysis tools for proteomic data, including Mascot, SEQUEST, Patternlab, MaxQuant, and Saint analysis; however, there is no standard for analysis, which may contribute to the variability between studies [148-152]. These proteins will then be questioned in regard to protein expression levels, modification, enrichment of networks and pathways, or changes in protein interaction networks. There are multiple methods of determining differences in protein levels, such as identifying outliers based on a fitted curve or standard deviation of a peptide ratio vs. abundance curve [150, 153]. Schmidt et al. offer a brief review of multiple software packages that can be utilized for analyzing mass spectrometry data [154].

\section{Overall challenges and limitations of proteomics}

Variability remains a major challenge in proteomic studies of neurological disorders. In fact, a meta-analysis of 87 synaptic proteomic studies found that only $6 \%$ of all dysregulated proteins were the same across studies. However, when looking at proteins similarly affected 


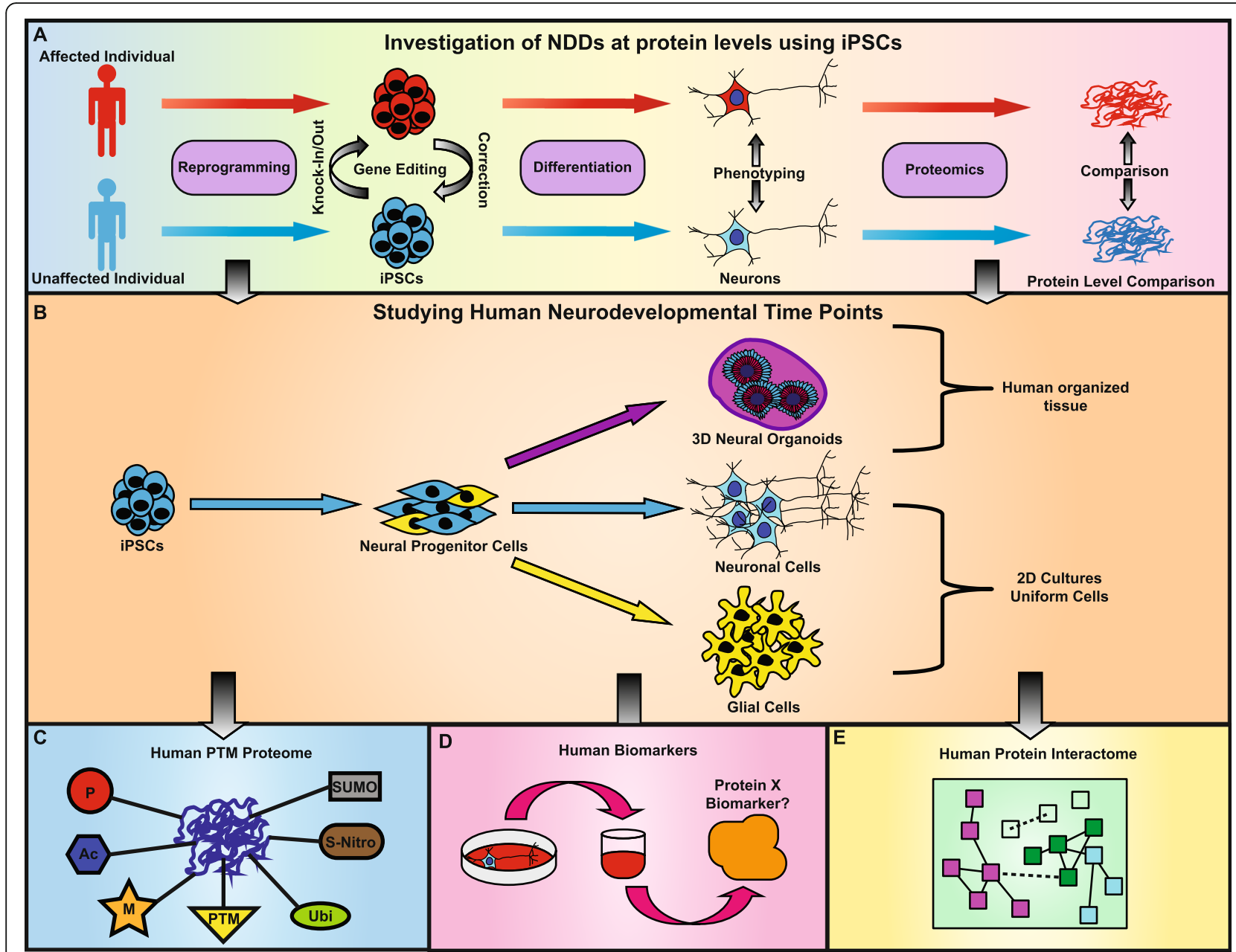

Fig. 4 Investigation of NDDs using human iPSCs and proteomics. (a) Biological samples from affected and unaffected individuals can be reprogrammed into iPSCS, which can be genetically edited to correct potential disease-relevant mutations or introduce gene disruptions and/or patient mutations. These iPSCs can then be differentiated into multiple cell types including neurons and then compared at the cellular and proteome levels. (b) The use of human iPSCs allows for the investigation of the proteome at different time points during development, including the iPSC stage, the neural progenitor stage, and the fully differentiated stage. Neuronal and glial 2D cell cultures can be studied, as well as 3D neural organoids that mimic human brain development. Proteomics with IPSC-derived neurons provides the potential to identify human PTM programs (c), human disease biomarkers (d), and human PINs (e)

across experiments, proteomic signatures could be identified for multiple neurological disorders [155]. Another major challenge is the heterogeneity of neurological disorders, which necessitates the use of strict criteria when choosing subjects. Major differences in these aspects can cause large variations in the proteome. Another technical challenge is the reduced sensitivity to detect low abundance proteins and splice isoforms. It also requires the use of uniform cells to identify robust changes in the proteome and therefore relies on good cell isolation techniques. Further, sample preparation presents a major source of variability, including loss of protein during processing and differences in trypsinization or desalting [156]. This issue can be overcome in some cases using SILAC-based MS or the use of isobaric labeling.
Labeling across all biological samples and replicates avoids the inherent variability of the MS instrumentation. The labeling of peptides also allows for combining all samples to be run as one, which reduces run time and variability; however, this presents a new problem, in which isobaric tags still have batch-to-batch variation [157]. A recent TMT-labeling study with human iPSCs looked at multi-batch effects and found that reproducibility of a single multiplexed TMT batch drastically falls when integrated with multiple TMT batches and a reference line is incorporated for normalization across runs [158]. Although many factors both methodological and experimental can create variability in mass spectrometry data, one tool is selected reaction monitoring mass spectrometry to validate specific proteins, for example, in 
post-mortem brains of ASD and control individuals [96]. Here, the majority of peptides and proteins were validated but the presence of some proteins did not match shotgun proteomics, revealing the potential for false negative and positive results.

\section{Conclusions}

The majority of iPSC studies on ASD are focused on genomic sequencing; however, there is much less research done at the protein level. The coupling of fractionation with mass spectrometry has drastically increased the resolution between proteins and the accuracy of quantification; however, future improvements to mass spectrometer technology will allow for reduced amounts of required sample. In this review, we provided multiple examples of how proteomics can be applied to study neurological disorders with iPSCs, as shown in Fig. 4. Using iPSCs, studying the proteome at different developmental time points in human neurons or glial cells is now a possibility (Fig. 4b). The ability to identify intracellular and extracellular protein levels and PTMs will drastically advance our knowledge of any brain disorder, including ASD (Fig. 4c, d). Further, 3D human brain organoids and spheroids improve the ability to study proteomic changes of an organized tissue that better mimics the human brain (Fig. 4b). However, the field still lacks the ability to perform singlecell proteomics with high precision and resolution. With proximity labeling, there will be a major focus on determine the protein interaction networks (PINs) for various neurological diseases (Fig. 4e), since this is still a poorly investigated area. Future studies should combine human iPSC-derived neurons with proximity labeling to identify human-specific PINs, which have been lacking due to the difficulties associated with human postmortem brain tissue. In conclusion, mass spectrometry opens major avenues of research into the proteome and the use of human iPSC-derived neural cells presents the potential to study the human proteome. By combing these tools, we can attain far-reaching advancements in understanding the pathophysiology of neurodevelopmental and neurodegenerative neurological disorders.

\footnotetext{
Abbreviations

ASD: Autism spectrum disorder; iPSC: Induced pluripotent stem cells; NDD: Neurodevelopmental disorder; SCZ: Schizophrenia; PTM: Posttranslation modification; MS: Mass spectrometry; LC-ESI: Liquid chromatography-electrospray ionization; MALDI: Matrix-assisted laser desorption/ionization; MS/MS: Tandem mass spectrometry; LFQ: Label-free quantification; AD: Alzheimer's disease; iTRAQ: Isobaric tags for relative and absolute quantitation; TMT: Tandem mass tag; SILAC: Stable isotope labeling by/with amino acids in cell cultures; PPI: Protein-protein interaction; $2 \mathrm{H}$ : Twohybrid; Y2H: Yeast two-hybrid; Co-IP: Coimmunoprecipitation;

APEX: Ascorbate peroxidase; BiolD: BirA* biotin ligase; NPC: Neural progenitor cells; PIN: Protein interaction network; SMA: Spinal muscular atrophy
}

\section{Authors' contributions}

NM contributed to the conception and design of this review and drafted most the manuscript. JU and KKS contributed to the design of this review and helped to draft the manuscript. All authors have read and approved the final manuscript.

\section{Funding}

This study was funded by grants to KKS from CIHR, Ontario Brain Institute, and ERA-NET.

\section{Availability of data and materials \\ Not applicable}

Ethics approval and consent to participate

Not applicable

Consent for publication

Not applicable

\section{Competing interests}

The authors have no competing interests.

Received: 9 December 2019 Accepted: 6 April 2020

Published online: 21 April 2020

References

1. Kumar B, Prakash A, Sewal RK, Medhi B, Modi M. Drug therapy in autism: a present and future perspective. Pharmacol Rep. 2012;64:1291-304.

2. lakoucheva LM, Muotri AR, Sebat J. Getting to the cores of autism. Cell. Elsevier Inc. 2019;178:1287-98.

3. Chen JA, Peñagarikano O, Belgard TG, Swarup V, Geschwind DH. The emerging picture of autism spectrum disorder: genetics and pathology. Annu Rev Pathol Mech Dis. 2015;10:111-44.

4. Cheng N, Rho JM, Masino SA. Metabolic dysfunction underlying autism spectrum disorder and potential treatment approaches. Front Mol Neurosci. 2017:10:1-12.

5. Anagnostou E, Taylor MJ. Review of neuroimaging in autism spectrum disorders: what have we learned and where we go from here. Mol Autism. 2011;2:1-9.

6. Mitelman SA, Buchsbaum MS, Young DS, Haznedar MM, Hollander E, Shihabuddin $L$, et al. Increased white matter metabolic rates in autism spectrum disorder and schizophrenia. Brain Imaging Behav. Springer US. 2018;12:1290-305.

7. Velmeshev D, Schirmer L, Jung D, Haeussler M, Perez Y, Mayer S, et al. Single-cell genomics identifies cell type-specific molecular changes in autism. Science (80- ). 2019;364:685-9.

8. Derosa BA, El Hokayem J, Artimovich E, Garcia-Serje C, Phillips AW, Van Booven D, et al. Convergent pathways in idiopathic autism revealed by time course transcriptomic analysis of patient-derived neurons. Sci Rep. Springer US. 2018;8:1-15

9. Quesnel-Vallières M, Weatheritt RJ, Cordes SP, Blencowe BJ. Autism spectrum disorder: insights into convergent mechanisms from transcriptomics. Nat Rev Genet. Springer US. 2019;20:51-63.

10. Liu Y, Beyer A, Aebersold R. Review on the dependency of cellular protein levels on mRNA abundance. Cell. Elsevier Inc. 2016;165:535-50.

11. Pontén F, Gry M, Fagerberg L, Lundberg E, Asplund A, Berglund L, et al. A global view of protein expression in human cells, tissues, and organs. Mol Syst Biol. 2009;5:1-9.

12. Ramsköld D, Wang ET, Burge CB, Sandberg R. An abundance of ubiquitously expressed genes revealed by tissue transcriptome sequence data. PLoS Comput Biol. 2009:5:1-11.

13. Lundberg E, Fagerberg L, Klevebring D, Matic I, Geiger T, Cox J, et al. Defining the transcriptome and proteome in three functionally different human cell lines. Mol Syst Biol. 2010;6:1-10.

14. Vogel C, Marcotte EM. Insights into the regulation of protein abundance from proteomic and transcriptomic analyses. Nat Rev Genet. 2012;13: 227-32

15. Deribe $Y L$, Pawson T, Dikic I. Post-translational modifications in signal integration. Nat Struct Mol Biol. Nature Publishing Group. 2010;17:666-72.

16. Ciechanover A. Proteolysis from the lysosome to. Mol Cell Biol. 2005;6:9. 
17. Krishnan A, Zhang R, Yao V, Theesfeld CL, Wong AK, Tadych A, et al. Genome-wide prediction and functional characterization of the genetic basis of autism spectrum disorder. Nat Neurosci. 2016;19.

18. Chang J, Gilman SR, Chiang AH, Sanders SJ, Vitkup D. Genotype to phenotype relationships in autism spectrum disorders. Nat Neurosci. 2015; 18:191-8.

19. Satterstrom FK, Kosmicki JA, Wang J, Breen MS. Novel genes for autism implicate both excitatory and inhibitory cell lineages in risk. bioRxiv. 2018;1-52.

20. Glish GL, Vachet RW. The basics of mass spectrometry in the twenty- first century. 2003;2:140-150.

21. Woods AG, Wetie AGN, Sokolowsk I, Russell S, Ryan JP, Michel TM, et al. Mass spectrometry as a tool for studying autism spectrum disorder Truncation Protein-protein interactions covalent or noncovalent, transient or stable Methylation, acetylation myristoylation Mass spectr. J Mol Psychiatry. 2013;1.

22. Catherman AD, Skinner OS, Kelleher NL. Top down proteomics: facts and perspectives. Biochem. Biophys. Res. Commun. 2014.

23. Silva JC, Gorenstein MV, Li GZ, Vissers JPC, Geromanos SJ. Absolute quantification of proteins by LCMSE: a virtue of parallel MS acquisition. Mol Cell Proteomics. 2006;5:144-56.

24. Mann M, Jensen ON. Proteomic analysis of post-translational modifications. 2Nature. Biotechnol. 2003;21:255-61.

25. Latosinska A, Vougas K, Makridakis M, Klein J, Mullen W, Abbas M, et al. Comparative analysis of label-free and 8-plex iTRAQ approach for quantitative tissue proteomic analysis. PLoS One. Public Library of Science. 2015;10.

26. Savas JN, Wang YZ, DeNardo LA, Martinez-Bartolome S, McClatchy DB, Hark $\mathrm{TJ}$, et al. Amyloid accumulation drives proteome-wide alterations in mouse models of Alzheimer's disease-like pathology. Cell Rep. Elsevier B.V. 2017;21: 2614-27.

27. Reim D, Distler U, Halbedl S, Verpelli C, Sala C, Bockmann J, et al. Proteomic analysis of post-synaptic density fractions from Shank3 mutant mice reveals brain region specific changes relevant to autism spectrum disorder. Front Mol Neurosci. 2017:10:1-10

28. Kirkpatrick DS, Gerber SA, Gygi SP. The absolute quantification strategy: a general procedure for the quantification of proteins and post-translational modifications. Methods. 2005;35:265-73.

29. Ross PL, Huang YN, Marchese JN, Williamson B, Parker K, Hattan S, et al. Multiplexed protein quantitation in Saccharomyces cerevisiae using aminereactive isobaric tagging reagents. Mol Cell Proteomics. 2004;3:1154-69.

30. Wiese S, Reidegeld KA, Meyer HE, Warscheid B. Protein labeling by ITRAQ: a new tool for quantitative mass spectrometry in proteome research. Proteomics. 2007;7:340-50.

31. Thompson A, Schäfer J, Kuhn K, Kienle S, Schwarz J, Schmidt G, et al. Tandem mass tags: a novel quantification strategy for comparative analysis of complex protein mixtures by MS/MS. Anal Chem. 2003;75:1895-904.

32. Ong SE, Blagoev B, Kratchmarova I, Kristensen DB, Steen H, Pandey A, et al. Stable isotope labeling by amino acids in cell culture, SILAC, as a simple and accurate approach to expression proteomics. Mol Cell Proteomics. 2002;: $: 376-86$

33. Zhang G, Bowling H, Hom N, Kirshenbaum K, Klann E, Chao MV, et al. Indepth quantitative proteomic analysis of de novo protein synthesis induced by brain-derived neurotrophic factor. J Proteome Res. American Chemical Society. 2014;13:5707-14.

34. Park JE, Tse SW, Xue G, Assisi C, Maqueda AS, Ramon GPX, et al. Pulsed SILAC-based proteomic analysis unveils hypoxia- and serum starvationinduced de novo protein synthesis with PHD finger protein 14 (PHF14) as a hypoxia sensitive epigenetic regulator in cell cycle progression. Oncotarget. 2019:(22):10, 2136.

35. Yi JJ, Paranjape SR, Walker MP, Choudhury R, Wolter JM, Fragola G, et al. The autism-linked UBE3A T485A mutant E3 ubiquitin ligase activates the Wnt/Bcatenin pathway by inhibiting the proteasome. J Biol Chem. American Society for Biochemistry and Molecular Biology Inc. 2017;292:12503-15.

36. Chaput D, Kirouac LH, Bell-Temin H, Stevens SM, Padmanabhan J. SILACbased proteomic analysis to investigate the impact of amyloid precursor protein expression in neuronal-like B103 cells. Electrophoresis. 2012;33(24): 3728-37.

37. Liao L, Park SK, Xu T, Vanderklish P, lii JRY. Quantitative proteomic analysis of primary neurons reveals diverse changes in synaptic protein content in fmr1 knockout mice. 2008;105:15281-6.

38. Tang B, Wang $T$, Wan $H$, Han L, Qin X, Zhang $Y$, et al. Fmr1 deficiency promotes age-dependent alterations in the cortical synaptic proteome. Proc Natl Acad Sci U S A. National Academy of Sciences. 2015;112:E4697-06.
39. Rayavarapu S, Coley W, Cakir E, Jahnke V, Takeda SNI, Aoki Y, et al. Identification of disease specific pathways using in vivo SILAC proteomics in dystrophin deficient mdx mouse. Mol Cell Proteomics. 2013;12(5):1061-73.

40. McClatchy DB, Liao L, Park SK, Xu T, Lu B, Yates JR. Differential proteomic analysis of mammalian tissues using SILAM. PLoS One. 2011;6(1):e16039. https://doi.org/10.1371/journal.pone.0016039.

41. McClatchy DB, Yates JR. Stable isotope labeling of mammals (SILAM). Cold Spring Harb Protoc. 2008.

42. Lu XM, Tompkins RG, Fischman AJ. SILAM for quantitative proteomics of liver Akt1/PKBa after burn injury. Int J Mol Med. 2012;29:461-71.

43. Krüger M, Moser M, Ussar S, Thievessen I, Luber CA, Forner F, et al. SILAC mouse for quantitative proteomics uncovers kindlin-3 as an essential factor for red blood cell function. Cell. 2008.

44. Zhao Y, Jensen ON. Modification-specific proteomics: Strategies for characterization of post-translational modifications using enrichment techniques. Proteomics. 2009;20:4632-41.

45. Kelley AR, Bach SBH, Perry G. Analysis of post-translational modifications in Alzheimer's disease by mass spectrometry. Biochim Biophys Acta - Mol Basis Dis. Elsevier. 1865:2019:2040-7.

46. Sambataro F, Pennuto M. Post-translational modifications and protein quality control in motor neuron and polyglutamine diseases. Front $\mathrm{Mol}$ Neurosci. 2017;10:1-13.

47. Arrington JV, Hsu CC, Elder SG, Andy TW. Recent advances in phosphoproteomics and application to neurological diseases. Analyst. Royal Society of Chemistry. 2017;142:4373-87.

48. Dammer EB, Lee AK, Duong DM, Gearing M, Lah JJ, Levey Al, et al. Quantitative phosphoproteomics of Alzheimer's disease reveals cross-talk between kinases and small heat shock proteins. Proteomics. 2015;15:508-19.

49. Perluigi $\mathrm{M}$, Barone E, Di Domenico F, Butterfield DA. Aberrant protein phosphorylation in Alzheimer disease brain disturbs pro-survival and cell death pathways. Biochim Biophys Acta - Mol Basis Dis. 1862;2016:1871-82.

50. Chen LL, Wang YB, Song JX, Deng WK, Lu JH, Ma LL, et al. Phosphoproteome-based kinase activity profiling reveals the critical role of MAP2K2 and PLK1 in neuronal autophagy. Autophagy. 2017:13:1969-80.

51. Matic K, Eninger T, Bardoni B, Davidovic L, Macek B. Quantitative phosphoproteomics of murine Fmr1 -KO cell lines provides new insights into FMRP-dependent signal transduction mechanisms. J Proteome Res. 2014:13:4388-97.

52. Collins MO, Yu L, Coba MP, Husi H, Campuzano I, Blackstock WP, et al. Proteomic analysis of in vivo phosphorylated synaptic proteins. J Biol Chem. 2005;280:5972-82.

53. Li J, Wilkinson B, Clementel VA, Hou J, O'Dell TJ, Coba MP. Long-term potentiation modulates synaptic phosphorylation networks and reshapes the structure of the postsynaptic interactome. Sci Signal. 2016;9:1-14.

54. Amal H, Barak B, Bhat V, Gong G, Joughin BA, Feng G, et al. Shank3 mutation in a mouse model of autism leads to changes in the S-nitrosoproteome and affects key proteins involved in vesicle release and synaptic function. Mol Psychiatry. Springser US; 2018;

55. Amal H, Gong G, Gjoneska E, Lewis SM, Wishnok JS, Tsai LH, et al. Snitrosylation of E3 ubiquitin-protein ligase RNF213 alters non-canonical Wnt/Ca + 2 signaling in the P301S mouse model of tauopathy. Trans Psychiatry. Springer US. 2019;9.

56. Sessa A, Fagnocchi L, Mastrototaro G, Andreazzoli M, Zippo A, Broccoli V, et al. SETD5 regulates chromatin methylation state and preserves global transcriptional fidelity during brain development and neuronal wiring 88 Neuron. Elsevier Inc. 2019;104:271-289.e13.

57. Mehla J, Caufield JH, Sakhawalker N, Uetz P. A comparison of two hybrid approaches for detecting protein- protein interactions. Methods Enzym. 2017:333-58.

58. Sakai Y, Shaw CA, Dawson BC, Dugas DV, Al- Z, Hill DE, et al. Protein interactome reveals converging molecular pathways among autism disorders. Sci Transl Med. 2011;3:86ra49.

59. Corominas $R$, Yang $X$, Lin GN, Kang $S$, Shen $Y$, Ghamsari L, et al. Protein interaction network of alternatively spliced isoforms from brain links genetic risk factors for autism. Nat Commun. Nature Publishing Group. 2014;5:1-12.

60. Morris JH, Knudsen GM, Verschueren E, Johnson JR, Cimermancic P, Greninger $\mathrm{AL}$, et al. Affinity purification-mass spectrometry and network analysis to understand protein-protein interactions. Nat Protoc. 2014;9:2539-54.

61. Shanks NF, Savas JN, Maruo T, Cais O, Hirao A, Oe S, et al. Report differences in AMPA and kainate receptor interactomes facilitate identification of AMPA receptor auxiliary subunit GSG1L. CellReports. The Authors; 2012;1:590-598. 
62. Husi H, Ward MA, Choudhary JS, Blackstock WP, Grant SGN. Proteomic analysis of NMDA receptor-adhesion protein signaling complexes. Nat Neurosci. 2000;3:661-9.

63. Collins MO, Husi H, Yu L, Brandon JM, Anderson CNG, Blackstock WP, et al. Molecular characterization and comparison of the components and multiprotein complexes in the postsynaptic proteome. 2006:97:16-23.

64. Fernández E, Collins MO, Uren RT, Kopanitsa M V., Komiyama NH, Croning MDR, et al. Targeted tandem affinity purification of PSD-95 recovers core postsynaptic complexes and schizophrenia susceptibility proteins. Mol Syst Biol. 2009;5.

65. Bayés Á, Van De Lagemaat LN, Collins MO, Croning MDR, Whittle IR, Choudhary JS, et al. Characterization of the proteome, diseases and evolution of the human postsynaptic density. Nat Neurosci. 2011;14:19-21.

66. Bayés À, Collins MO, Galtrey CM, Simonnet C, Roy M, Croning M, et al. Human post-mortem synapse proteome integrity screening for proteomic studies of postsynaptic complexes. Mol Brain. 2014;7:88.

67. Li J, Zhang W, Yang H, Howrigan DP, Wilkinson B, Souaiaia T, et al. Spatiotemporal profile of postsynaptic interactomes integrates components of complex brain disorders. Nat Neurosci. 2017;20:1150-61.

68. Berg JM, Lee C, Chen L, Levine MS, Wohlschlegel JA, Geschwind DH, et al. JAKMIP1, a novel regulator of neuronal translation, modulates synaptic function and autistic-like behaviors in mouse. 2015;1173-91.

69. Soppa U, Schumacher J, Ortiz VF, Pasqualon T, Tejedor FJ, Becker W. The down syndrome-related protein kinase DYRK1A phosphorylates p27 Kip1and cyclin D1 and induces cell cycle exit and neuronal differentiation. Cell Cycle. 2014;13:2084-100

70. Park J, Sung JY, Park J, Song WJ, Chang S, Chung KC. Dyrk1a negatively regulates the actin cytoskeleton through threonine phosphorylation of $\mathrm{N}$ WASP. J Cell Sci. 2012;125:67-80.

71. Guard SE, Poss ZC, Ebmeier CC, Pagratis M, Simpson H, Taatjes DJ, et al. The nuclear interactome of DYRK1A reveals a functional role in DNA damage repair. Sci Rep. 2019;9:1-12.

72. Zhang Y, Marc J, Olav V, Frode M, Jan SB, Faraone SV. Effect of disease associated SLC9A9 mutations on protein - protein interaction networks implications for molecular mechanisms for ADHD and autism. ADHD Atten Deficit Hyperact Disord. Springer Vienna. 2019;11:91-105.

73. Li J, Ma Z, Shi M, Malty RH, Aoki H, Minic Z, et al. Identification of human neuronal protein complexes reveals biochemical activities and convergent mechanisms of action in autism spectrum disorders. Cell Syst. Elsevier Inc. 2015;1:361-74

74. Gonzalez-Lozano MA, Koopmans F, Sullivan PF, Protze J, Krause G, Verhage $M$, et al. Stitching the synapse: cross-linking mass spectrometry into resolving synaptic protein interactions. Sci Adv. 2020;6:1-15.

75. Brown EA, Lautz JD, Davis TR, Gniffke EP, Vanschoiack AAW, Neier SC, et al. Clustering the autisms using glutamate synapse protein interaction networks from cortical and hippocampal tissue of seven mouse models. Molecular Autism. 2018:1-16.

76. Han S, Li J, Ting AY. ScienceDirect Proximity labeling : spatially resolved proteomic mapping for neurobiology. Curr Opin Neurobiol. Elsevier Ltd. 2018;50:17-23.

77. Roux KJ, Kim DI, Raida M, Burke B. A promiscuous biotin ligase fusion protein identifies proximal and interacting proteins in mammalian cells. J Cell Biol. 2012;196:801-10.

78. Martell JD, Deerinck TJ, Sancak Y, Poulos TL, Mootha VK, Sosinsky GE, et al. Engineered ascorbate peroxidase as a genetically encoded reporter for electron microscopy. Nat Biotechnol. 2012;30:1143-8.

79. Li P, Li J, Wang L, Di LJ. Proximity labeling of interacting proteins: application of BiolD as a discovery tool. Proteomics. 2017;17:1-10.

80. Regulator K, Sensitivity PI, Narita T, Nussenzweig A, Lukas J, Choudhary C. DNA repair network analysis reveals shieldin as a key regulator of NHEJ and PARP inhibitor sensitivity. Cell. Elsevier Inc.; 2018;173:972-974.e23.

81. Filamin-a I, Remodeling F, Van VAR, Giordano F, Gerlo S, Samali A, et al. The ER stress sensor PERK coordinates ER-plasma membrane contact site formation through interaction with filamin-A and F-actin remodeling. Mol Cell. Elsevier. 2017;65:885-899.e6.

82. Liu X, Salokas K, Tamene F, Jiu Y, Weldatsadik RG, Öhman T, et al. An APMS- and BiolD-compatible MAC-tag enables comprehensive mapping of protein interactions and subcellular localizations. Nat Commun. Springer US. 2018;9.

83. Kim BR, Coyaud E, Laurent EMN, St-germain J, Laar E Van De, Tsao M, et al. Identification of the SOX2 interactome by BioID reveals EP300 as a mediator of SOX2-dependent squamous differentiation and lung squamous cell carcinoma growth * ${ }^{*}$. 2017; 1864-88.

84. Chou C, Zhang Y, Umoh ME, Vaughan SW, Lorenzini I, Liu F, et al. TDP-43 pathology disrupts nuclear pore complexes and nucleocytoplasmic transport in ALS/FTD. Nat Neurosci. Springer US. 2018;21.

85. Markmiller S, Soltanieh S, Server KL, Mak R, Jin W, Fang MY, et al. Contextdependent and disease-specific diversity in protein interactions within stress granules. Cell. 2018;172:590-604.e13.

86. Branon TC, Bosch JA, Sanchez AD, Udeshi ND, Svinkina T, Carr SA, et al. Efficient proximity labeling in living cells and organisms with TurbolD. Nat Biotechnol. Nature Publishing Group. 2018;36:880-98.

87. Ting AY, Stawski PS, Draycott AS, Udeshi ND, Lehrman EK, Wilton DK, et al. Proteomic analysis of unbounded cellular compartments: synaptic clefts. Cell. Elsevier Inc. 2016;166:1295-1307.e21.

88. Fazal FM, Han S, Parker KR, Kaewsapsak P, Xu J, Boettiger AN, et al. Atlas of subcellular RNA localization revealed by APEX-seq. Cell. Elsevier Inc. 2019; 178(2):473-90.

89. Hamdan H, Lim BC, Torii T, Joshi A, Konning M, Smith C, et al. Mapping axon initial segment structure and function by multiplexed proximity biotinylation. Nat Commun. Springer US. 2020;11.

90. Uezu A, Kanak DJ, Bradshaw TWA, Soderblom EJ, Catavero CM, Burette AC, et al. Identification of an elaborate complex mediating postsynaptic inhibition. Science (80- ). 2016;353:1123-9.

91. Spence EF, Dube S, Uezu A, Locke M, Soderblom EJ, Soderling SH. In vivo proximity proteomics of nascent synapses reveals a novel regulator of cytoskeleton-mediated synaptic maturation. Nat Commun. Springer US. 2019;10:1-16

92. Reeck GR, Fish L. A statistical analysis of the amino acid compositions of proteins. Int J Pept Protein Res. 1973;5:109-17.

93. Chen C, Perrimon N. Proximity-dependent labeling methods for proteomic profiling in living cells. WIREs Dev Biol 2017. 2017;6:1-10.

94. Branon TC, Bosch JA, Sanchez AD, Udeshi ND, Svinkina T, Steven A, et al. Directed evolution of TurbolD for efficient proximity labeling in living cells and organisms; 2017. p. 1-27.

95. Kim JH, Lee SR, Li LH, Park HJ, Park JH, Lee KY, et al. High cleavage efficiency of a 2A peptide derived from porcine teschovirus-1 in human cell lines, zebrafish and mice. PLoS One. 2011;6:1-8.

96. Abraham JR, Szoko N, Barnard J, Rubin RA, Schlatzer D, Lundberg K, et al. Proteomic investigations of autism brain identify known and novel pathogenetic processes. Sci Rep. Springer US. 2019:1-11.

97. Hutsler JJ, Love T, Zhang H. Histological and magnetic resonance imaging assessment of cortical layering and thickness in autism spectrum disorders. Biol Psychiatry. 2007;61:449-57.

98. Hutsler JJ, Zhang H. Increased dendritic spine densities on cortical projection neurons in autism spectrum disorders. Brain Res. Elsevier B.V. 2010;1309:83-94.

99. Wu YE, Parikshak NN, Belgard TG, Geschwind DH. Genome-wide, integrative analysis implicates microRNA dysregulation in autism spectrum disorder. Nat Neurosci. Nature Publishing Group. 2016;19:1463-76.

100. Broek JA, Guest PC, Rahmoune H, Bahn S. Proteomic analysis of post mortem brain tissue from autism patients: evidence for opposite changes in prefrontal cortex and cerebellum in synaptic connectivity-related proteins. Mol Autism. 2014;5:41.

101. Behan ÁT, Byrne C, Dunn MJ, Cagney G, Cotter DR. Proteomic analysis of membrane microdomain-associated proteins in the dorsolateral prefrontal cortex in schizophrenia and bipolar disorder reveals alterations in LAMP, STXBP1 and BASP1 protein expression. Mol Psychiatry. 2009;14:601-13.

102. Föcking M, Lopez LM, English JA, Dicker P, Wolff A, Brindley E, et al. Proteomic and genomic evidence implicates the postsynaptic density in schizophrenia. Mol Psychiatry. 2015;20:424-32.

103. Föcking M, Dicker $P$, Lopez LM, Hryniewiecka M, Wynne K, English JA, et al. Proteomic analysis of the postsynaptic density implicates synaptic function and energy pathways in bipolar disorder. Transl Psychiatry. Nature Publishing Group. 2016;6.

104. Pichitpunpong C, Thongkorn S, Kanlayaprasit S, Yuwattana W, Plaingam W, Sangsuthum S, et al. Phenotypic subgrouping and multi-omics analyses reveal reduced diazepam-binding inhibitor (DBI) protein levels in autism spectrum disorder with severe language impairment. PLoS One. 2019;14:1-30.

105. Chen Y-N, Du H-Y, Shi Z-Y, He L, He Y-Y, Wang D. Serum proteomic profiling for autism using magnetic bead - assisted matrix - assisted laser 
desorption ionization time - of - flight mass spectrometry : a pilot study. World J Pediatr. 2018:233-7.

106. Taurines R, Dudley E, Conner AC, Grassl J, Jans T, Guderian F, et al. Serum protein profiling and proteomics in autistic spectrum disorder using magnetic bead-assisted mass spectrometry. 2010;249-255.

107. Cortelazzo A, Guerranti R, Felice C De, Signorini C, Leoncini S, Pecorelli A, et al. A plasma proteomic approach in Rett syndrome: classical versus preserved speech variant. 2013;2013.

108. Shen L, Feng C, Zhang K, Chen Y, Gao Y. Proteomics study of peripheral blood mononuclear cells ( PBMCs) in autistic children. 2019;13:1-16.

109. Huerta ODR, Fernández AG, De Torre MJ, Gil AA, Navero JLP. Metabolic profiling in children with autism spectrum disorder with and without mental regression : preliminary results from a cross - sectional case control study. Metabolomics. Springer US. 2019;15:1-11.

110. Wei H, Sun S, Li Y, Yu S. Reduced plasma levels of microtubule-associated STOP/MAP6 protein in autistic patients. Psychiatry Res. Elsevier. 2016;245: $116-8$.

111. Emanuele E, Colombo R, Martinelli V, Brondino N, Marini M, Boso M, et al. Elevated urine levels of bufotenine in patients with autistic spectrum disorders and schizophrenia. Neuroendocrinol Lett. 2010;31:117-21.

112. Kałuzna-Czaplińska J, Michalska M, Rynkowski J. Determination of tryptophan in urine of autistic and healthy children by gas chromatography/mass spectrometry. Med Sci Monit. 2010;16:488-92.

113. With C. Stress O. Altered vascular phenotype in autism. 2019;63:4-7.

114. Castagnola M, Messana I, Inzitari R, Fanali C, Cabras T, Morelli A, et al. Hypophosphorylation of salivary peptidome as a clue to the molecular pathogenesis of autism spectrum disorders. 2008;

115. Levin Y, Wang L, Schwarz E, Koethe D, Leweke FM, Bahn S. Global proteomic profiling reveals altered proteomic signature in schizophrenia serum. Mol Psychiatry. Nature Publishing Group. 2010;15:1088-100.

116. Huang JTJ, Leweke FM, Oxley D, Wang L, Harris N, Koethe D, et al. Disease biomarkers in cerebrospinal fluid of patients with first-onset psychosis. PLoS Med. 2006;3:2145-58.

117. Ardhanareeswaran K, Mariani J, Coppola G, Abyzov A, Vaccarino FM. Human induced pluripotent stem cells for modelling neurodevelopmental disorders. Nat Rev Neurol. 2017;13:265-78.

118. Dolmetsch R, Geschwind DH. The human brain in a dish: the promise of iPSC-derived neurons. Cell. 2011;145:831-4.

119. Takahashi K, Yamanaka S. Induction of pluripotent stem cells from mouse embryonic and adult fibroblast cultures by defined factors. Cell. 2006;126:663-76.

120. Takahashi K, Tanabe K, Ohnuki M, Narita M, Ichisaka T, Tomoda K, et al. Induction of pluripotent stem cells from adult human fibroblasts by defined factors. Cell. 2007;131:861-72.

121. Yu J, Vodyanik MA, Smuga-Otto K, Antosiewicz-Bourget J, Frane JL, Tian S, et al. Induced pluripotent stem cell lines derived from human somatic cells. Science (80- ). 2007;318:1917-20.

122. Haase A, Olmer R, Schwanke $K$, Wunderlich S, Merkert S, Hess C, et al. Generation of induced pluripotent stem cells from human cord blood. Cell Stem Cell. 2009;5:434-41.

123. Tao Y, Zhang S-C. Neural subtype specification from human pluripotent stem cells. Stem Cell. Elsevier Inc. 2016;19:573-86.

124. Bahmad H, Hadadeh O, Chamaa F, Cheaito K, Darwish B, Makkawi AK, et al. Modeling human neurological and neurodegenerative diseases: From induced pluripotent stem cells to neuronal differentiation and its applications in neurotrauma. Front Mol Neurosci. 2017;10.

125. Zhang Y, Pak CH, Han Y, Ahlenius H, Zhang Z, Chanda S, et al. Rapid singlestep induction of functional neurons from human pluripotent stem cells. Neuron. 2013;78:785-98.

126. Lesur A, Domon B. Advances in high-resolution accurate mass spectrometry application to targeted proteomics. Proteomics. 2015;15:880-90.

127. Budnik B, Levy E, Harmange G, Slavov N. SCoPE-MS: mass spectrometry of single mammalian cells quantifies proteome heterogeneity during cell differentiation. Genome Biol. Genome Biology. 2018;19:1-12.

128. Aiuto LD, Zhi Y, Das DK, Wilcox MR, Jon W, Mcclain L, et al. Large-scale generation of human iPSC-derived neural stem cells / early neural progenitor cells and their neuronal differentiation. Organogenesis. 2014; 10(4):365-77.

129. Martı A, Paz D, Esteller M, Ausio J. MeCP2 : the long trip from a chromatin protein to neurological disorders. 2014;20.

130. Kim JJ, Savas JN, Miller MT, Hu X, Freitas BCG, Muotri AR, et al. Proteomic analyses reveal misregulation of LIN28 expression and delayed timing of glial differentiation in human iPS cells with MECP2 loss-of-function. PLoS One. 2019:1-23.

131. Varderidou-Minasian S, Hinz L, Hagemans D, Posthuma D, Altelaar M, Heine VM. Quantitative proteomic alterations of human iPSC-based neuronal development indicate early onset of Rett syndrome. bioRxiv. 2019;603647.

132. Silva MC, Cheng C, Mair W, Almeida S, Fong H, Biswas MHU, et al. Human iPSC-derived neuronal model of tau-A152T frontotemporal dementia reveals tau-mediated mechanisms of neuronal vulnerability. Stem Cell Reports. The Authors. 2016:7:325-40.

133. Bogetofte $H$, Jensen $P$, Okarmus J, Ida S, Agger M, Ryding $M$, et al. Perturbations in RhoA signalling cause altered migration and impaired neuritogenesis in human iPSC-derived neural cells with PARK2 mutation. Neurobiol Dis. Elsevier. 2019;132:104581.

134. Fuller HR, Mandefro B, Shirran SL, Gross AR. Spinal muscular atrophy patient iPSC-Derived motor neurons have reduced expression of proteins important in neuronal development. 2016;9:1-15.

135. Varderidou-minasian S, Pasterkamp RJ. Deciphering the protein dynamics and molecular determinants of iPSC-derived neurons. bioRxiv. 2019;1-39.

136. Krencik R, Hokanson KC, Narayan AR, Dvornik J, Rooney GE, Rauen KA, et al. Dysregulation of astrocyte extracellular signaling in Costello syndrome. Sci Transl Med. 2015;7:286ra66-286ra66.

137. Shirotani K, Matsuo K, Ohtsuki S, Masuda T, Asai M, Kutoku Y, et al. A simplified and sensitive method to identify Alzheimer's disease biomarker candidates using. 2017;162:391-394.

138. Lancaster MA, Renner M, Martin C, Wenzel D, Bicknell LS, Hurles ME, et al. Cerebral organoids model human brain development and microcephaly. Nature. Nature Publishing Group. 2013;501:373-9.

139. Paşca AM, Sloan SA, Clarke LE, Tian Y, Makinson CD, Huber N, et al. Functional cortical neurons and astrocytes from human pluripotent stem cells in 3D culture. Nat Methods. 2015;12:671-8.

140. Qian X, Song H, Ming G. Brain organoids: advances, applications and challenges. Development. 2019;146:dev166074.

141. Koo B, Choi B, Park H, Yoon K-J. Past, Present, and future of brain organoid technology. Mol Cells. 2019;42:617-27.

142. Karzbrun E, Reiner O. Brain organoids-a bottom-up approach for studying human neurodevelopment. MDPI AG: Bioengineering; 2019.

143. Nascimento JM, Saia-Cereda VM, Sartore RC, da Costa RM, Schitine CS, Freitas HR, et al. Human cerebral organoids and fetal brain tissue share proteomic similarities. Front Cell Dev Biol. 2019;7:1-16.

144. Chen M, Lee H, Moo L, Hanlon E, Stein T, Xia W. Common proteomic profiles of induced pluripotent stem cell-derived three- dimensional neurons and brain tissue from Alzheimer patients. J Proteomics. Elsevier. 2018;182:21-33.

145. Johnstone M, Vasistha NA, Barbu MC, Dando O, Burr K, Christopher E, et al. Reversal of proliferation deficits caused by chromosome 16p13.11 microduplication through targeting NFKB signaling: an integrated study of patient-derived neuronal precursor cells, cerebral organoids and in vivo brain imaging. Mol Psychiatry. Nature Publishing Group. 2019;24: 294-311.

146. Schaffer LV, Millikin RJ, Miller RM, Anderson LC, Fellers RT, Ge Y, et al. Identification and quantification of proteoforms by mass spectrometry. Proteomics. 2019;19:1-15.

147. Vaudel M, Sickmann A, Martens L. Current methods for global proteome identification. Expert Rev Proteomics. 2012;9:519-32.

148. Perkins DN, Pappin DJC, Creasy DM, Cottrell JS. Probability-based protein identification by searching sequence databases using mass spectrometry data. Electrophoresis. 1999;20:3551-67.

149. Carvalho PC, Fischer JSG, Chen El, Yates JR, Barbosa VC. PatternLab for proteomics: a tool for differential shotgun proteomics. BMC Bioinformatics. 2008:9:1-14.

150. Cox J, Mann M. MaxQuant enables high peptide identification rates, individualized p.p.b.-range mass accuracies and proteome-wide protein quantification. Nat Biotechnol. 2008:26:1367-72.

151. Choi H, Larsen B, Lin Z-Y, Breitkreutz A, Mellacheruvu D, Fermin D, et al. SAINT: Probabilistic scoring of affinity purification - mass spectrometry data. Nat Methods2. 2011;8:70-3.

152. Eng JK, McCormack AL, Yates JR. An approach to correlate tandem mass spectral data of peptides with amino acid sequences in a protein database. J Am Soc Mass Spectrom. 1994;5:976-89.

153. Zhang Y, Askenazi M, Jiang J, Luckey CJ, Griffin JD, Marto JA. A robust error model for iTRAQ Quantification reveals divergent signaling between 
oncogenic FLT3 mutants in acute myeloid leukemia. Mol Cell Proteomics. 2010;9:780-90

154. Schmidt A, Forne I, Imhof A. Bioinformatic analysis of proteomics data. BMC Syst Biol. 2014;8:167-79.

155. Reig-Viader R, Sindreu C, Bayés À. Synaptic proteomics as a means to identify the molecular basis of mental illness: are we getting there? Prog Neuro-Psychopharmacology Biol Psychiatry. Elsevier. 2018;84:353-61.

156. Piehowski PD, Petyuk VA, Orton DJ, Xie F, Moore RJ, Ramirez-Restrepo M, et al. Sources of technical variability in quantitative LC-MS proteomics: human brain tissue sample analysis. J Proteome Res. American Chemical Society. 2013;12:2128-37.

157. O'Connell JD, Paulo JA, O'Brien JJ, Gygi SP. Proteome-wide evaluation of two common protein quantification methods. J Proteome Res. American Chemical Society. 2018;17:1934-42.

158. Brenes A, Hukelmann J, Bensaddek D, Lamond Al. Multibatch TMT reveals false positives, batch effects and missing values. Mol Cell Proteomics. NLM (Medline). 2019;18:1967-80.

\section{Publisher's Note}

Springer Nature remains neutral with regard to jurisdictional claims in published maps and institutional affiliations.

Ready to submit your research? Choose BMC and benefit from:

- fast, convenient online submission

- thorough peer review by experienced researchers in your field

- rapid publication on acceptance

- support for research data, including large and complex data types

- gold Open Access which fosters wider collaboration and increased citations

- maximum visibility for your research: over $100 \mathrm{M}$ website views per year

At $\mathrm{BMC}$, research is always in progress.

Learn more biomedcentral.com/submissions 